\title{
A Manutenção do Capital de Giro Próprio e Sua Apropriação no Custo Rudolf Ornstein*
}

1. A Manutenção do Capital de Giro Proprio como Fator do Custo. 2. Metodologia. 3. Distribuição da Manutenção de Capital de Giro Próprio sobre os Centros de Custo. 4. Exemplo Prático de Distribuição da MCGP sóbre os Centros. 5. O Custo do Produto. 6. Apropriação Global da MCGP no Overhead Administrativo.

Em fins do ano de 1968, o Govêrno Federal publicou o Decretolei $n^{\circ} 401$, permitindo às emprêsas do País contabilizar como parcela negativa do rédito tributável um montante correspondente, em tese, à perda inflacionária do capital de giro próprio, sofrida durante o exercício. Em outras palavras, admitiu-se que as emprêsas deduzissem do seu lucro uma importância denominada manutenção do capital de giro próprio (MCGP), para manter, em têrmos exatos, o poder aquisitivo dêste capital.

Desta forma, as autoridades responsáveis pelo destino da economia da nação vieram finalmente ao encontro de uma já antiga reivindicação dos empresários. Estes estavam clamando, com justa razão, contra a tributação daquela parcela de seus lucros que foi consumida, inevitàvelmente, para a reconstituição monetária do seu capital de giro, exposto a um aviltamento contínuo durante os atos de troca.

* Professor da Faculdade de Ciencias Econômicas da Universidade Federal do Rio Grande do Sul.

R. Adm. Emp., Rio de Janeiro, 10(4): 103-119, out./dez. 1970 
Parecia que, com a promulgação do referido decreto-lei, em conjunto com a legislação anteriormente existente relativa à reavaliação dos bens imobilizados, os empresários nacionais estariam razoàvelmente protegidos contra a perda de substância à qual êles se viam indefesamente expostos durante muitos anos de inflação contínua.

Infelizmente, algumas semanas mais tarde, o Govêrno limitou, pelo Decreto-lei $n^{\circ} 433$, a aplicabilidade do primeiro decreto, restringindo a formação da reserva para a MCGP, isenta da tributação, para $20 \%$ do lucro bruto tributável. Assim, as emprêsas com elevado CGP ou com baixa margem de lucro encontram-se sensivelmente prejudicadas. Para ficar dentro do espírito dos dois decretos, o lucro deveria ser 5 vêzes superior à reserva a formar. Para muitas emprêsas esta proporção é inatingível, enquanto que para outras, cuja posição no mercado permite aumentar seus preços até a altura da relação indicada, o Decretolei $\mathrm{n}^{\circ} \mathbf{4 3 3}$ constitui um estímulo inflacionário. Neste último caso, a recuperação de cada cruzeiro adicional para a formação da reserva de MCGP implica em aumento do preço de venda de cinco cruzeiros (ou de aproximadamente seis cruzeiros, contando o ICM).

\section{A Manutenção do Capital de Gino Próprio como Fator do Custo}

Independentemente do montante que, sob aspectos legais, pode ser abatido do rédito, a importância contabilizada para o fim da manutenção do capital de giro diminui o lucro da emprêsa.

Para efeito de cálculo, esta parcela negativa do rédito, sendo intimamente ligada às atividades especificas da emprêsa (admitindo-se que $o$ ativo realizável se destine exclusivamente a estas atividades) deve ser classificada como custo do exercício. Este custo pode ser interpretado como sendo causado pelo desgaste do capital investido em bens circulantes, similar à depreciação que reflete a perda de capital devido ao desgaste através do tempo, de bens imobilizados.

A similaridade entre a MCGP e a depreciação é ainda mais extensa: igual à última, a MCGP constitui um custo calculatório 
(não exigindo dispêndios), e é um custo fixo, em consequêencia da forma de sua apuração.

O curto espaço de tempo percorrido desde a regulamentação do assunto - pouco mais de um ano - ainda não permite formar uma opinião definitiva sôbre o tratamento calculatório que deve ser dado à MCGP dentro da sistemática da contabilidade de custos. Neste artigo partimos do ponto de vista de que a MCGP deve ser apropriada no custo da emprêsa, aparecendo já durante o exercício e não sòmente no seu fim, sendo registrado desde o início como componente negativo do rédito em todos os instrumentos de contrôle da gestão (balancetes, demonstrativos do rédito, relatórios mensais sôbre rentabilidade, etc.). Igualmente, e como consequiência lógica dêste primeiro passo, a MCGP, uma vez contabilizada, deve também ser imputada ao custo do output da emprêsa, ou seja, fazer obrigatòriamente parte do custo dos produtos fabricados, dos serviços prestados, etc.

Pretendemos nestas linhas examinar as modalidades da contabilização e apropriação do custo da MCGP e seus reflexos sôbre a política de preço, enfocando o problema particularmente do ponto de vista das emprêsas industriais, as quais, costumeiramente, dedicam especial atenção ao problema de custo, devido à maior complexidade do assunto neste setor das atividades econômicas.

\section{Metodologia}

Para apropriar a MCGP no custo de uma emprêsa industrial procede-se de acôrdo com as seguintes linhas gerais:

a) Estabelece-se uma previsão do montante da MCGP para o exercício entrante, usando os dados do balanço de encerramento do exercício anterior.

b) Durante o exercício debita-se, mensalmente, um doze avos da previsão como custo operacional, creditando-se como contrapartida uma conta transitória no passivo. Esta conta, de fato, tem caráter de uma provisão.

c) No encerramento do exercício calcula-se a MCGP de acôrdo com os preceitos legais dos Decretos-leis ns. 401 e 433, regis- 
trando-se a diferença entre o valor encontrado e o montante acumulado durante 0 ano na conta de provisão como variação de custo.

d) A quota mensal contabilizada conforme b) deve ser inscrita nos instrumentos analíticos de custo, do contrôle setorial da emprêsa na área da contabilidade industrial (contabilidade departamental ou setorial, mapa de localização de custos etc.)

O problema da apropriação no custo, da MCGP, reside justamente no método a ser adotado para a execução do último dos quatro passos acima citados.

Nota-se que o sistema acima traçado em muito se assemelha à forma normalmente usada para a contabilização e apropriação das depreciações. Da mesma forma, a MCGP é também tratada como custo fixo durante o ano, sujeito a retificaçбes na ocasião do encerramento do período. A diferença principal entre as duas espécies de custo, porém, reside no item d) de nossa relação acima, ou seja, na forma a ser usada para fazer a distribuição setorial. Quanto à depreciação, nenhuma dúvida existe de que ela deva ser debitada proporcionalmente nos centros de custo que utilizam os bens depreciados, mas, quanto à MCGP, um procedimento análogo é muito discutível.

Inscrevendo as parcelas respectivas da MCGP nos custos primários dos centros da área industrial, elas passam através das rotinas comuns do cálculo para o custo de fabricação dos produtos elaborados, aumentando destarte o valor inventarial dêsses produtos. De um lado, êste fato é indesejável porque aumenta o lucro tributável e distribuível da emprêsa. De outro lado, para conhecer o custo real dos produtos e fixar-lhes o preço de venda, a inclusão de todos os custos, fixos e variáveis, é altamente recomendável e normalmente objetivado pelos empresários. Não desejando aumentar o valor das existências pela inclusão da MCGP, resta então como outra alternativa a inclusão da MCGP nas despesas gerais.

Dispomos, consequientemente, de acôrdo com o critério adotado, de duas modalidades de apropriar a MCGP no custo: 
- distribuí-la sôbre todos os centros onde existe capital em giro, com a vantagem de ter os custos mais exatos e os preços melhor calculados, especialmente na indústria de produção múltipla; ou

- apropriá-la globalmente, sacrificando a exatidão do cálculo, mas com a vantagem de diminuir o valor das existências de produtos.

Nas linhas que se seguem mostraremos as duas alternativas possiveis no tratamento da MCGP como custo operacional e examinaremos os respectivos prós e contras.

\section{Distribuição da MCGP sôbre os Centros de Custo}

Presumimos, para fins da exposição seguinte, que a emprêsa se serve do método do Mapa de Localização de Custos (MLC) para o contrôle contínuo de seus custos. Esta hipótese deve ser admitida como válida para a grande maioria das emprêsas industriais.

Optando pela primeira das duas alternativas discriminadas, uma quota mensal da MCGP deve ser distribuída sôbre os centros de custos que são considerados responsáveis pela existência e permanência do capital de giro. Antes de demonstrar a técnica,. aliás elementar, desta distribuição, temos que examinar a composição do capital de giro da emprêsa que dá origem ao custo de manutenção.

Dentro do espírito da legislação vigente - que, em têrmos largos, admite, aliás, definição idêntica à do conceito econômico - o capital de giro total de uma emprêsa industrial se compõe dos seguintes itens do ativo realizável:
a) matérias-primas
b) materiais auxiliares
c) produtos em fabricação
d) produtos acabados
e) devedores (clientes e outros)
f) disponível (caixa, bancos, etc.)
g) custos pré-pagos. 
Da soma dêstes valôres, constantes do balanço inicial do exercício, deduz-se o valor do passivo exigivel (depois de algumas exclusões e correções de menor importância), obtendo-se como diferença o capital de giro próprio.

Reconhecemos que esta maneira de computar aquela parcela do capital próprio que está sujeita a uma perda de substância, devido à ação corrosiva do processso inflacionário, é algo controvertido, mas, para fins práticos e nos têrmos legais existentes, o valor discriminado é definido como CGP com direito a uma taxa de manutenção.

Sendo o CGP já uma diferença entre dois somatórios, é óbvio que qualquer tentativa de identificar suas partes específicas com determinados componentes do ativo realizável não trará sucesso algum. Desta maneira, não cometemos nenhum êrro em atribuir o CGP a cada um dos itens do ativo, em proporção ao valor dos mesmos constantes do balanço, ou, em outras palavras, atribuímos o CGP percentualmente a cada item do ativo, de acôrdo com a sua participação no capital de giro total, antes de deduzir o passivo exigível.

Como agora poderemos usar êstes resultados para localizar a - MCGP nos diversos centros de custo da empresa industrial?

O seguinte raciocínio de alocação se oferece como o mais imediato: debitamos as parcelas da MCGP correspondente a

- matéria-prima ao centro de cưsto: depósito de matéria-prima

- material auxiliar ao centro de custo: almoxarifado de materiais

- produtos em fabricação: aos centros da área industrial onde êstes produtos foram inventariados

- produtos acabados ao centro de custo: estoque de produtos (ou similar)

- devedores (clientes) ao centro: departamento comercial 
- disponível

ao centro: administração geral

- transitório

ao centro: administração geral.

O esquema apresentado não deve ser interpretado como rígido; procuramos fornecer apenas uma idéia geral do procedimento. Cada emprêsa terá que adotar os critérios que melhor correspondam às condições particulares encontradas. Se, por exemplo, a emprêsa utiliza um mapa de custos cujo plano de centros não prevê um centro especial para a matéria-prima, a parcela da MCGP que recai sôbre êste elemento pode ser calculada em função direta do consumo, etc.

Quanto aos custos pré-pagos, fàcilmente poderá ser encontrado algum critério para identificá-los com um centro específico, ao invés de um débito indireto ao setor administrativo, etc. Finalmente, ainda seria possível proceder-se a uma revisão da existência do ativo em giro durante o exercício (por exemplo, para o segundo semestre) e alterar os coeficientes de alocação de acôrdo, ou então, outras variantes mais complexas do sistema.

Recomendamos ainda, para fins da apropriação da MCGP no custo, que as restrições impostas pelo Decreto-lei $n^{\circ} 433$ não sejam levadas em conta.

Este decreto deturpa o fundamento econômico da solução dada ao problema da perda de substância do capital de giro, e, pelo menos para fins circulatórios, não deve ser considerado. Sòmente após o encerramento do balanço, quando se verificar que o rédito contábil não é suficientemente elevado para permitir o abatimento do total da MCGP, é que se pode proceder aos necessários reajustes no sentido do referido Decreto-lei. Achamos também que, da mesma forma, a exclusão dos créditos com prazo superior de 120 dias (Decreto-lei $n^{9} 433$, art. 4) é improcedente para efeitos do cálculo do custo da MCGP.

\section{Exemplo Prático de Distribuição da MCGP sôbre os Centros}

O balanço inicial de uma emprêsa industrial apresenta o seguinte aspecto (em $\mathrm{Cr} \$ 1.000)$ : 


\section{Ativo}

Imobilizado:

Prédios e Terrenos:

Máquinas e Equip.:

Capital em siro:

Caixa e Bancos;

Devedores:

Matéi ia-Prima:

Material Auxiliar:

Prod. em fabricação:

Prod. acabados:

Custos pré-pagos

Total:
Passivo:

Não Exigivel:

Capital Nominal:

Reservas:

Exigfvel:

Fornecedores:

130

Bancos:

Financiamentos:

Diversos:

100

$30 \quad 330$

Capital de Giro Próprio = Capital em Giro menos Exigível

$$
\begin{aligned}
\text { CGP } & =550-330 \\
& =220
\end{aligned}
$$

Taxa inflacionária prevista para o exercício $=25 \%$ MCGP $=25 \%$ do CGP $=0,25 \times 220=55$.

Distribuindo êste montante da MCGP sôbre o capital de giro inicialmente existente, obtemos uma taxa de $10 \%$ (ou seja $\frac{55}{550}$ ) a qual, aplicada sôbre os diversos componentes do capital de giro, fornece o seguinte quadro:

Aplicação do MCGP durante o exercício (em Cr\$ 1.000):

Anual Mensal (arredondado)

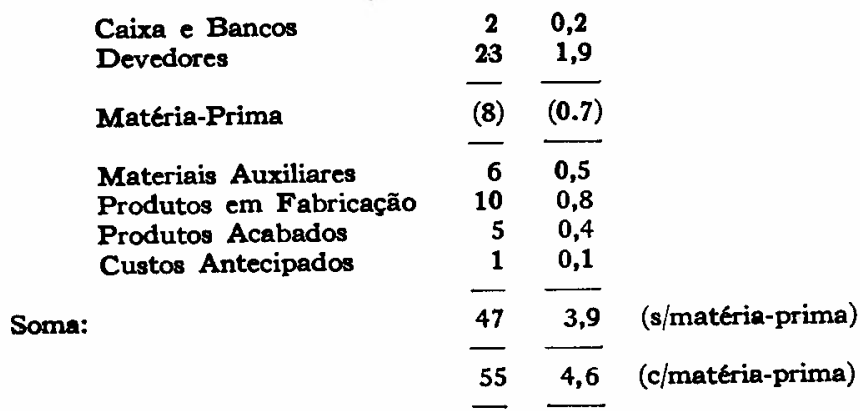


Suponhamos agora que a emprêsa possua cinco Centros de Custo:

a) Almoxarifado, responsável pelos materiais auxiliares;

b) Produção I e

c) Produção II, responsáveis em partes iguais pelos produtos em fabricação;

d) Departamento Comercial, responsável pelos produtos prontos e devedores;

e) Administração Geral, responsável pela caixa e pelos custos pré-pagos.

A matéria-prima não é guardada no Almoxarifado, sendo entregue diretamente ao Setor de Produção. Assim sendo, elimina-se a parcela da MCGP correspondente à matéria-prima da distribuição sôbre os centros, restando a importância de 47,0 por ano, ou seja 3,9 por mês a alocar (veja exercício acima). Os produtos prontos, no caso em foco, foram colocados sob responsabilidade do Departamento Comercial, já que a programação da produção se guia exclusivamente nas ordens emitidas pelo setor de Vendas.

O Mapa de Localização de Custos, de um certo mês, terá então o seguinte aspecto:

\begin{tabular}{|c|c|c|c|c|c|c|}
\hline & Almox. & $\begin{array}{c}\text { b } \\
\text { Prod. } 1\end{array}$ & $\begin{array}{c}-4 \\
\text { Prod, II }\end{array}$ & $\begin{array}{c}d \\
\text { Dep. Com. }\end{array}$ & Adm. Geral & Total \\
\hline Custos Primários & 5,0 & 10,0 & 15,0 & 7,0 & 13,0 & 50,0 \\
\hline MCQP & 0,5 & 0,4 & 0,4 & 2,3 & 0.3 & 3,8 \\
\hline Rereiro Ahmoxarifado & $\longrightarrow$ & 2,1 & 2,6 & 0,7 & 0,1 & 5,5 \\
\hline sams & 5,5 & 12,5 & 18,0 & 10.0 & 13,4 & 58,4 \\
\hline \multirow{2}{*}{\multicolumn{2}{|c|}{ Horesfmidquires durante o mist }} & 2.500 & 8.000 & & & .500 \\
\hline & & 5,0 & 3,0 & & & \\
\hline
\end{tabular}


Esclarecemos:

- a MCGP sôbre produtos em fabricação foi repartida sôbre os dois centros de produção;

- no Departamento Comercial encontramos a MCGP sôbre devedores $(1,9)$ e mais sôbre produtos prontos $(0,4)$;

- a Administração Geral inclui Caixa e Custos pré-pagos $(0,2+0,1)$;

- a linha Custos Primários inclui tôdas as espécies de custos do mês que figuram no mapa, com exceção da MCGP;

- o rateio do almoxarifado obedece a critérios alheios a esta exposição.

Observa-se que no mês aqui analisado a MCGP incide com $7,8 \%$ sôbre os custos primários. Sem a inclusão da mesma, os custos unitários dos centros produtivos baixariam para 4,80 e 2,90, como é fácil de se demonstrar.

\section{O Custo do Produto}

Nas próximas linhas pretendemos mostrar, através de um modêlo simples, o impacto da MCGP sôbre o custo e, consequientemente, sôbre o preço calculado de um produto industrial.

Compulsando os dados do parágrafo precedente, notamos que falta ainda apropriar a importância de 8,00 por ano, relativa a MCGP da matéria-prima.

O orçamento da emprêsa prevê, para o exercício, um consumo de matéria-prima de 250,00 (Cr\$ 1.000), de maneira que a MCGP onera a mesma em

$$
\frac{8}{250}-3,2 \%
$$

Calculamos agora o custo de um produto fabricado - Produto XY: 


\begin{tabular}{lcc} 
& $\begin{array}{c}\text { Com inclusão da } \\
\text { MCGP }\end{array}$ & Sem MCGP \\
\hline & Cr\$ & Cr\$ \\
Consumo de Matéria-Prima & 5,00 & 5,00 \\
MCGP s/Matéria-Prima (3,2\%) & 0,16 & $\frac{9,60}{8,10}$ \\
2 horas-máquina P I & 10,00 & 8,10 \\
3 horas-máquina P II & 9,00 & 22,70 \\
\hline Soma (Custo Produção): & 24,16 & \\
\hline
\end{tabular}

As duas somas representam o custo total da área fabril do referido produto, ou seja, o valor que seria empregado para inventariar o artigo. A diferença entre os dois casos é de $\mathrm{Cr} \$ 1,46$.

Esta diferença, ou seja, um impacto de $6,4 \%$ no custo de produção pode ser considerado como normal nas condições industriais geralmente prevalecentes.

Admitindo agora que a emprêsa, para determinar o preço de venda de seus artigos, empregue qualquer uma das rotinas usuais do custeio integral; os custos do Departamento Comercial e da Administração Geral devem ser agregados ao custo de produção. Tendo em vista que aquêles dois componentes, muitas vêzes denominados de Despesas Gerais, se acham igualmente onerados pelo custo da MCGP, torna-se claro que a diferença acima deve aumentar ainda mais.

Usando, por exemplo, o método simples da apropriação dos custos administrativos em proporção à hora-máquina, temos o seguinte resultado:

Departamento Comercial, por hora-máquina $=\frac{10.000}{8.500}=1,18$

$\begin{array}{rlrl}\text { Administração Geral, por hora-máquina } & =\frac{13.400}{8.500} & =\frac{1,58}{2,76} \\ \text { TOTAL, por hora-máquina } & =2,5\end{array}$

O valor correspondente, excluindo a MCGP, seria de Cr\$2,40 por hora-máquina. 
Continuamos agora nosso cálculo de custo do Produto XY:

\begin{tabular}{|c|c|c|}
\hline & $\begin{array}{l}\text { Com inclusão da } \\
\text { MCGP }\end{array}$ & Sem MCGP \\
\hline $\begin{array}{l}\text { Custo de produção } \\
\text { Custos administrativos e comerciais } \\
5 \text { horas-máquina a } \operatorname{Cr} \$ 2,76 \\
5 \text { horas máquina a } \operatorname{Cr} \$ 2,40\end{array}$ & $\begin{array}{r}\mathrm{Cr} \$ \\
24,16 \\
13,80\end{array}$ & $\begin{array}{r}\mathrm{Cr} \$ \\
22,70\end{array}$ \\
\hline Soma (Custo Total): & 37,96 & 34,70 \\
\hline
\end{tabular}

A diferença entre os dois resultados atinge agora $\mathrm{Cr} \$ 3,26$ por unidade, ou seja, $9,4 \%$.

Se êste custo fôr tomado como base para a determinação do preço de venda, o que sucede muito freqüentemente, verificamos que os preços resultantes, com inclusão da MCGP no custo, serão aproximadamente em $10 \%$ superior aos preços calculados com exclusão da MCGP.

O exemplo aqui apresentado foi escolhido por demonstrar com bastante nitidez a influência da MCGP na formação dos custos e preços. Admite-se que a diferença indicada de $10 \%$ é superior à média de muitos casos observados, mas um impacto da MCGP sôbre custos e preços ao redor de 5 a $6 \%$ é comum.

\section{Apropriação Global da MCGP no "Overhead" Administrativo}

Esta é a segunda das duas alternativas mencionadas no fim do § 3 desta exposição. Omite-se a análise da MCGP em função de seus componentes e também a distribuição sôbre os diversos centros de custo da emprêsa.

A manutenção do CGP é agora considerada como um custo do setor administrativo ou financeiro, e, usando o mapa de localização de custos, debitado integralmente ao centro respectivo. $O$ método conduz a uma maior diluição dêsse custo no que tange ao cálculo dos produtos e de seus preços, sendo que êstes últimos não refletem mais o impacto individualizado da MCGP sôbre os vários centros e sôbre os produtos fabricados nesses centros. 
Usando os dados do exemplo do parágrafo anterior, o mapa de custo terá então o seguinte aspecto (em $\mathrm{Cr} \$ 1.000)$ :

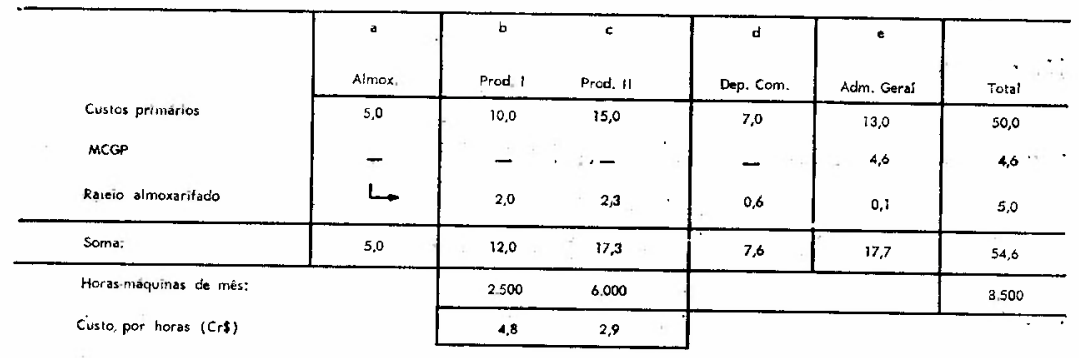

Introduzindo êstes valôres no cálculo do custo do produto $\mathrm{XY}$, temos:

\begin{tabular}{lr} 
Matéria-Prima & $\operatorname{Cr} \$ \mathbf{5 , 0 0}$ \\
\hline horas-máquina P.I & 9,60 \\
3 horas-máquina P.II & 8,10 \\
Custos administrativo & \\
5 horas a 2,97 & $\mathbf{1 4 , 8 5}$ \\
\multicolumn{1}{c}{ Custo total: } & $\operatorname{Cr} \$ \frac{37,05}{}$
\end{tabular}

Confrontando êste custo com o custo total calculado pelo primeiro método (da distribuição da MCGP sôbre todos os centros de custo), constatamos uma diferença a menos de

$$
38,16=37,55=\operatorname{Cr} \$ 0,61 \text {, ou seja, de } 1,5 \% .
$$

Considerando que todo o custo da emprêsa foi incluído no mapa de custos, torna-se evidente que essa diferença a menos no produto $\mathrm{XY}$ deve ser compensada por uma diferença a mais em qualquer outro produto fabricado no mesmo período.

Este fato confirma nossa afirmação anterior de que o tratamentò da MCGP como custo geral, ou overhead administrativo conduz a uma distorção dos custos e preços individuais, particularmente nos casos em que uma emprêsa industrial fabrica simultâneamente, ou em conjunto, vários produtos diferentes. A discrepância entre os diversos artigos dependerá, como se pode 
notar, da proporção entre matéria-prima e horas-máquinas insumidas para os produtos e, também, do sistema calculatório adotado.

\section{Resumo}

- Adotou-se, neste artigo, a tese de que uma provisão para a manutenção do capital de giro próprio deve ser incluída no custo operacional das emprêsas.

- Este custo deve ser transferido para o custo do produto fabricado (ou serviço prestado), especialmente quando se determina o custo tendo em vista a formação dos preços de venda.

- Podemos proceder à inclusão da MCGP no custo do produto por dois caminhos diferentes:

A. Distribuição sôbre os centros de custo mediante rateio da provisão para a MCGP em função dos componentes do ativo em giro.

B. Incorporação dessa provisão no custo geral administrativo da emprêsa.

1. O incremento do custo do produto devido ao emprêgo da primeira modalidade acima citada conduz necessàriamente a valôres mais elevados da avaliação das existências de produtos semi-elaborados e acabados. Sempre que esta superavaliação fôr julgada como inconveniente, a avaliação das existências terá que ser feito por um cálculo independente do cálculo industrial.

2. O incremento do custo do produto devido ao emprêgo da segunda modalidade significa uma diluição da MCGP sôbre os diversos produtos da emprêsa. $O$ fenômeno é tanto mais pronunciado quanto mais divergente fôr a composição técnica do custo dos produtos.

3. No caso das emprêsas com grande variedade de artigos fabricados e de emprêsas com estoque de produtos rela- 
tivamente pequeno, ou com rotação rápida dos estoques, optamos sempre pelo primeiro método.

- Os preços calculados com a inclusão da MCGP fornecerão uma idéia mais realista sôbre o rédito genuíno à disposição da emprêsa, após o ato da venda.

- Foi apresentado um exemplo esquemático que ilustra os métodos calculatórios. Para fins de confronto, repetimos os resultados:

Custo do Produto XY:

10 método (distribuição da MCGP sôbre os centros): Cr\$ 38,16

$2^{\circ}$ método (inclusão da MCGP no overhead admin.) Cr\$37,55

$3^{\prime \prime}$ método (sem inclusão da MCGP no custo do prod.): Cr\$34,70

Nas linhas aqui apresentadas não pretendemos emitir opinião definitiva sôbre o problema do tratamento a ser dado à MCGP. Sabemos que existem métodos calculatórios mais requintados para solucionar o assunto e pontos de vista diferentes para enfocar o problema. Desejamos apenas formular uma posição e contribuir para discussões em tôrno de um problema relativamente nôvo.

O que achamos inadmissível é que a MCGP seja encarada como um simples abatimento do lucro para fins da tributação, deixando de lado a eminente influência econômica que ela necessàriamente deve exercer sôbre o sistema de custos e réditos.

\section{Comentário do Artigo a Manutenção do Capital de Giro Próprio e sua Apropriação no Custo}

\section{Yuichi R. Tsukamoto}

Não concordo com a concepção fundamental do prof. Ornstein de que o capital de giro próprio é apropriável. Na minha opinião, o capital de giro é um valor residual entre o realizável e o exigivel a curto prazo e, por isso, não poderá e nem deverá ser apropriado especificamente a diversos itens do ativo, como o 
autor tenta fazer. Para citar um exemplo simples, vamos tomar o saldo credor de fornecedores. A linha de crédito de fornecedores é aproveitada para caixa, devedores, ou matéria-prima? Ninguém pode determinar essa relação. Entretanto, tenta determinar essas relações através de um método simples de rateio percentual entre os itens do ativo realizável.

E as mudanças de composição do capital de giro durante o ano? Elas não têm influência no custo de manutenção do capital de giro? Mesmo aceitando a tese fundamental, como refletir essas mudanças no esquema de apropriação?

\section{Resposta ao Comentário do Prof. Yuichi R. Tsukamoto}

\section{Rudolf Ornstein}

Concordo, em tese, com a opinião do prof. Tsukamoto, de que o capital de giro próprio não é apropriável. Este fato, aliás, está reconhecido em uma observação constante do parágrafo 4 dêste artigo.

O que se tenta fazer aqui, porém, não é apropriar o CGP, mas sim o custo da manutenção ou estabilização dêsse capital. Para essa finalidade, recorre-se a uma técnica que encontra aplicação generalizada em todos os sistemas calculatórios, ou seja, o emprêgo de números proporcionais. Êstes números, usados sob as mais diversas denominações (chaves de rateio, fatôres de alocação, coeficientes de distribuição, etc.) servem como instrumento de cômputo sempre que se trate de imputar um custo indireto a vários diferentes portadores de custo. Sem o emprêgo dessas relações proporcionais todos os processos usuais de cálculo tornar-se-iam inoperantes, sobrevivendo exclusivamente o método dos custos singulares (prime-costs), comprovadamente insatisfatório. Admitindo como válida a rejeição absoluta de um rateio percentual, pràticamente todos os sistemas existentes de cálculo deviam ser condenados. No caso em foco, procede-se como se procede em inúmeros casos similares, usando a técnica do rateio, consciente do fato de que não existe nenhuma maneira de determinar os valôres absolutos. 
Quanto às mudanças de composição do capital de giro durante o exercício, nada impede que se proceda a um recálculo dos coeficientes em intervalos convenientes. Essa possibilidade é especificamente mencionada neste artigo, no penúltimo item do parágrafo 4. Nota-se, porém, que neste caso haverá divergência entre o valor aplicado da MCGP e a taxa estabelecida pelo Decretolei $n^{\circ} 401$.

\section{VAMOS REUNIR O BELO AO ÚTIL?}

Os cartões de natal da UNICEF são reproduções de obrasprimas da arte contemporânea, impressas segundo os mais modernos processos.

E não têm fins lucrativos. O seu dinheiro ajudará a vestir, educar e alimentar os 900.000 .000 de crianças que a UNICEF assiste em todo o mundo.

Você conhece alguma promoção mais compativel com o espírito do Natal?

Caixa com 10 cartões pequenos com envelopes $\operatorname{Cr} \$ 6,00$ Caixa com 10 cartões grandes com envelopes $\operatorname{Cr} \$ 10,00$ Agendas

Cr $\$ 12,00$

A venda nas livrarias da Fundação Getúlio Vargas. 